\title{
Resistance to Azithromycin and $\beta$-Lactam Antibiotics by Clinical Isolates of $E$. coli Isolated from Dhaka, Bangladesh
}

\author{
Sunjukta Ahsan ${ }^{1 *}$, Mayen Uddin ${ }^{1}$, Juthika Mandal ${ }^{1}$ and Marufa Zerin Akhter ${ }^{1}$ \\ ${ }^{I}$ Department of Microbiology, University of Dhaka, Dhaka 1000, Bangladesh
}

\begin{abstract}
Antibiotic resistant $E$. coli are prevalent in Bangladesh. The indiscriminate use of antimicrobials and ready availability of over the counter drugs are responsible for this. This study was conducted to investigate the susceptibility of clinical Escherichia coli to the antibiotics Imipenem, Ceftriaxone, Ceftazidime and Azithromycin. Kirby-Bauer disk diffusion method was used to determine sensitivity to antimicrobials. Agar based assay was employed for the detection of efflux pumps. PCR was used amplify antibiotic resistance genes.All isolates were resistant to Ceftriaxone whereas most were sensitive to Imipenem. The MICs of Ceftazidime and Azithromycin ranged between $128 \mu \mathrm{g} / \mathrm{ml}$ and $256 \mu \mathrm{g} / \mathrm{ml}$. The prevalence of ${ }^{2}$-lactamase producers was $57.89 \%$ with $36.84 \%$ of the isolates exhibiting ESBL activity. No specific correlation could be found between plasmid sizes and antibiotic resistance patterns. Efflux pump was found to be involved in Azithromycin resistance in $63.15 \%$ of the isolates. The gene for phosphotransferase, $m p h(A)$ was the most common among the macrolide modifying genes, being present in $73.68 \%(14 / 19)$ of the isolates followed by both $\mathrm{erm}(\mathrm{A})$ anderm(C) esterases each present in $10.53 \%(2 / 19)$ isolates. This study concluded that clinical isolates of $E$. coli in Bangladesh could be resistant to multiple classes of antibiotics through different mechanisms of resistance.
\end{abstract}

Keywords: ESBL, Carbapenem, MIC, Macrolide, Efflux pump.

\section{Introduction}

Antibiotic resistance results when bacteria change themselves to get protection from an antibiotic. As a result, antibiotics capable of killing bacteria have no ability to combat bacterial pathogen. Antimicrobial resistance, which is noticeable in the whole world, threatens prevention and treatment of infections. Newer form of resistance is also a concern, as mechanisms of resistances are emerging globally ${ }^{1}$. Large scale use of antibiotics has been found for several decades. Inadvertent use of antibiotics accompanied by irresponsible monitoring of antibiotic use has worsened the present situation and has resulted in multi-drug resistance ${ }^{2,3,4}$.

There are various mechanisms, which can lead to antibiotic resistance such as modification of the target site of the antibiotic, degradation of antibiotic molecule through enzymes and active efflux of antibiotic molecule outside of the microbial cells ${ }^{5}$. Traditional mechanisms of antibiotic resistance can occur intrinsically such as through biofilm formation or having outer cell membrane in Gram negative bacteria or through mobile genetic elements ${ }^{6-9}$. Most commonly found antibiotic resistance can be exerted through production of enzymes such as ${ }^{2}$-lactamase which has become a global concern now-a-days ${ }^{10,11}$ and bacteria containing extended spectrum ${ }^{2}$-lactamase have been found showing resistance to a number of antibiotics ${ }^{12-14}$. Efflux mechanism can contribute to reduction in antibiotic concentration from cytosol and the efflux system could be chromosomal or by mobile genetic elements ${ }^{15,16}$.
Escherichia coli, a member of the family Enterobacteriaceae exhibit drug resistance property through extended spectrum ${ }^{2}$ lactamases, esterases, phosphotransferases, efflux pumps and integrons ${ }^{17}$. This bacterium has been responsible for various diarrheal and infectious diseases in our country ${ }^{18}$. Antibiotic resistance found in clinical isolates in Bangladesh has worsened treatment processes ${ }^{19}$.

The present study aims to detect patterns of resistance in clinical E. coli isolates tothe antibiotics Ceftriaxone, Ceftazidime, Imipenem, and Azithromycin. The study also identified mediators of macrolide resistance such as plasmids, enzymes, integrons and efflux pumps.

\section{Materials and Methods}

Sample History

A total of nineteen clinical isolates were collected from a renowned hospital of Dhaka city, where the isolates were identified by biochemical and serological tests. Isolates were labeled as C1-C9 (Urinary Tract Infection), C10-C12 and C18 (Pus sample), C13 and C19 (Tracheal Swab), C14-C15 (Catheter Tip), C16 (Sputum) and C17 (High Vaginal Swab). Isolates were handled aseptically and maintained in glycerol broth in $-20^{\circ} \mathrm{C}$ as stock. All isolates were reconfirmed through biochemical tests before the present study was conducted. 


\section{Antibiotic Susceptibility Test}

Bacterial susceptibility to antimicrobial agents was determined by disk diffusion method ${ }^{20}$ and resistant, intermediately resistant and sensitive isolates were determined followingguidelines recommended by the Clinical Laboratory Standard Institute ${ }^{21}$ using commercially available antibiotic disks (Oxoid, UK). The antibiotic disks used in the study included Imipenem $(10 \mu \mathrm{g})$, Ceftriaxone (30 $\mathrm{g})$, Azithromycin $(15 \mu \mathrm{g})$, Ceftazidime $(30 \mu \mathrm{g})$. Bacterial lawn was prepared by inoculating the surface of Mueller Hinton agar (Oxoid, UK) plates with a 0.5 MacFarland standard culture using sterile cotton swab. Then antibiotic disks were aseptically placed on the bacterial lawn andEscherichia coli ATCC 25922 was used as a control during antibiotic susceptibility testing. Zone of inhibition was measured after overnight incubation at $37^{\circ} \mathrm{C}$.

\section{Minimum Inhibitory Concentration (MIC) of Selected Antibiotics}

Minimum inhibitory concentrations (MICs) are defined as the lowest concentration of antibiotic which inhibits clearly visible growth of the test organism after overnight incubation. The purpose of determining MIC was to identify specific ranges of concentration of antimicrobial agent (Azithromycin, Ceftriaxone, Ceftazidime and Imipenem) that inhibit the growth of bacteria in laboratory media. Stock solutions of Azithromycin, Ceftriaxone, Ceftazidime and Imipenem at concentrations of $100 \mathrm{mg} / \mathrm{ml}$ were prepared using sterile $0.9 \%$ saline water.Bacteriallawn of each test isolate was prepared from a culture equivalent of McFarland 0.5 standard and inoculated in media containing various concentrationsof antibiotics. After overnight incubation at $37^{\circ} \mathrm{C}$, the plates were observed for the presence or absence of growth in presence of different concentration of antibiotics.

Extended Spectrum ${ }^{2}$ Lactamase (ESBL) Assay

Bacterial lawns were prepared as already described here. Discs of Ceftriaxone, Ceftazidime and Amoxicillin-clavulanic acid were placed aseptically on the lawn. The plates were incubated at $37^{\circ} \mathrm{C}$ for 24 hours and observed for ESBL (Extended Spectrum ${ }^{2}$ Lactamase) activity.

\section{Plasmid Extraction}

Broth cultures oftest $E$. coli were prepared using Mueller Hinton Broth. Plasmids were extracted using the kit (Invisorb ${ }$, Germany) following the manufacturer's recommendations. Extracted plasmids were stored at $-20^{\circ} \mathrm{C}$.

\section{Efflux Pump Inhibition Assay for Macrolide by Esomeprazole}

Bacterial lawn was prepared on Mueller Hinton Agar plates containing various concentrations of Ethidium Bromide (EtBr) $(0.5,1.0,1.5,2.0$ and $2.5 \mu \mathrm{g} / \mathrm{ml})$. Overnight incubation was carried out at $37^{\circ} \mathrm{C}$ and penetration of light was impeded by covering the plates with opaque polythene. Then the EtBr containing plates were observed with a UV transilluminator ( $\mathrm{Gel}$ Doc, Bio-Rad, USA) for fluorescence. Again for observation of effect of Esomeprazole, cultures were patched with sterile cotton bud on MHA containing Esomeprazole at a concentration of $50 \mathrm{mg} /$ litre and Azithromycin at concentrations of $256 \mu \mathrm{g} / \mathrm{ml}$, $128 \mu \mathrm{g} / \mathrm{ml}, 64 \mu \mathrm{g} / \mathrm{ml}, 32 \mu \mathrm{g} / \mathrm{ml}, 16 \mu \mathrm{g} / \mathrm{ml}$, and $8 \mu \mathrm{g} / \mathrm{ml}$ and another control containing Azithromycin only at the same concentrations without Esomeprazole but containing $0.5 \mathrm{~N} \mathrm{NaCl}$, which acted as an inducer of efflux pump expression. After 24 hours of incubation at $37^{\circ} \mathrm{C}$ the plates were observed to determine the effect of Esomeprazole as a proton pump inhibitor on macrolide susceptibility of the test bacteria.

\section{Molecular Method to Detect Macrolide Resistance Genes}

Primer sequences and annealing temperatures for primers to amplify macrolide resistance genes are listed in Table 1. Primer pairs used in the PCR reactions in our current study were $m p h(\mathrm{~A})$, $m p h(\mathrm{~B}), \operatorname{erm}(\mathrm{A}), \operatorname{erm}(\mathrm{B}), \operatorname{erm}(\mathrm{C}), \operatorname{ere}(\mathrm{A})$ and ere(B). Annealing temperatures for each of the primer sets was set according to the directions to work correctly within a single reaction and amplicon sizes. At first, the PCR was carried out using templates from four isolates simultaneously in a single PCR tube to see if any amplification occurs in the desired region. After that, the positive set was repeated in a single PCR reaction using template DNA from single isolate.

\section{Results}

\section{Antimicrobial Resistance Pattern of E. coli Isolates}

According to the CLSI (Clinical and Laboratory Standards Institute) guideline ${ }^{21}$, clinical $E$. coli isolates were in general resistant toAzithromycin, Ceftazidime and Ceftriaxone but were sensitive to Imipenem.In this experiment four different antibiotics like Azithromycin, Ceftazidime, Ceftriaxone and Imipenemhave been used which have the MIC values of $8 \mu \mathrm{g} / \mathrm{ml}, 2 \mu \mathrm{g} / \mathrm{ml}, 2 \mu \mathrm{g} /$ $\mathrm{ml}$ and $4 \mu \mathrm{g} / \mathrm{ml}$, respectively. By following this value, clinical isolates of Escherichia coli have been distinguished into three categories - sensitive, intermediate and resistant to distinct antibiotics and the resistance pattern is shown in Figure 1.

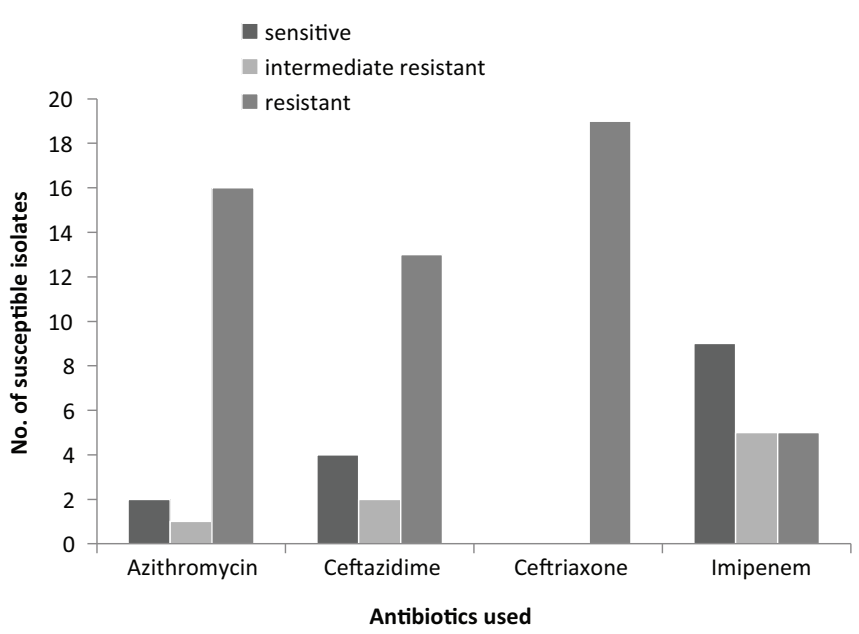

Figure 1. Antibiotic sensitivity patterns of clinical E. coli 


\section{Extended Spectrum ${ }^{2}$-lactamase (ESBL) Activity of the Isolates}

In this assay, 11 isolates $(\mathrm{C} 1, \mathrm{C} 3, \mathrm{C} 4, \mathrm{C} 7, \mathrm{C} 10, \mathrm{C} 11, \mathrm{C} 13, \mathrm{C} 15$, $\mathrm{C} 17, \mathrm{C} 18$ and $\mathrm{C} 19)$ were $^{2}$ lactamase producers and 7 isolates (C1, C4, C7, C10, C11, C17 and C18) were ESBL producers among the 19 isolates tested. One isolate exhibited ESBL activity against Ceftazidime whereas two isolates exhibited ESBL activity against Ceftriaxone. Four isolates exhibited ESBL activity against both Ceftriaxone and Ceftazidime. Figure 2 shows the behavior of the test isolates when tested for ESBL activity against Ceftriaxone and Ceftazidime.

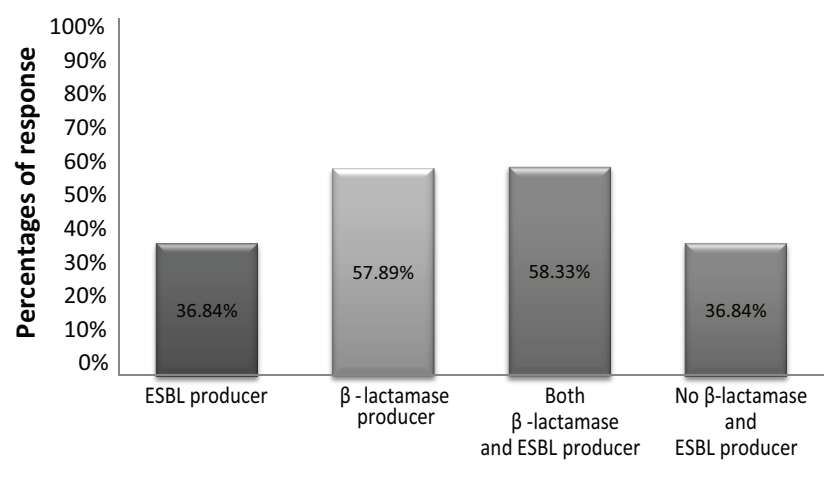

Response patterns of isolates on ESBL and $\beta$-lactamase

Figure 2. Percentages of ESBL and ${ }^{2}$ - lactamase producers

\section{Efflux Pump Activity in Macrolide Resistant Isolate}

In order to determine whether the test isolates contained active efflux pumps, they were incubated in medium containing Ethidium bromide at a specific concentration. The assumption was that if efflux pump were present, Ethidium bromide would be pumped in and isolates would fluorescence under UV exposure. Nineteen isolates including E.coli ATCC 25922 were used in this study contained efflux pumps. Figure 3 shows presence of efflux pumps in the test isolates. Presence of efflux pump was confirmed by observing fluorescence of the 19 isolates in the presence of Ethidium bromide. But this was not enough to confirm that a mechanism requiring participation of the efflux pumps to pump out antibiotics will develop resistance in the bacterium.Thus a combination of Esomeprazole and Azithromycin was used test the involvement of efflux pump in pumping out of Azithromycin.In most of the isolates, comparing the MIC of Azithromycin alone, MIC of Azithromycin was found significantly reduced which shows that if efflux pump inhibitor

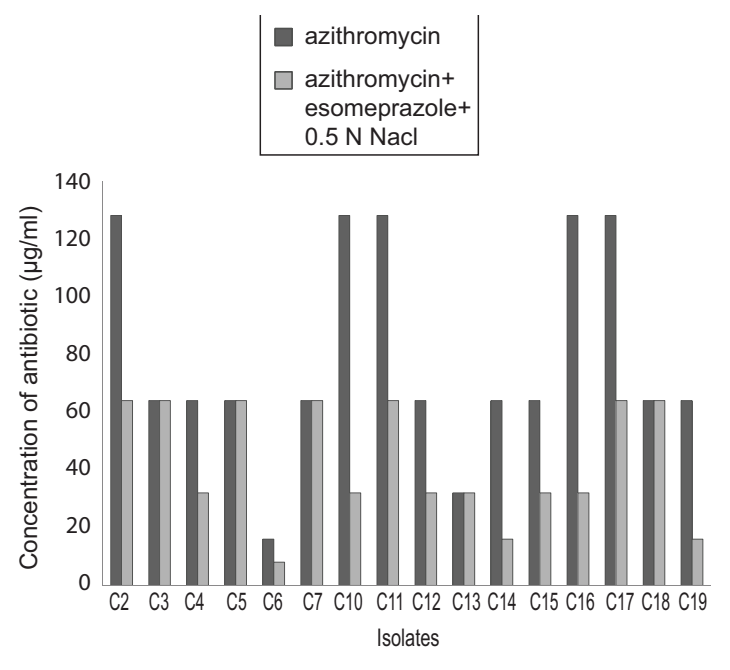

Figure 3. Effect of esomeprazole on efflux pump activity

was present, Azithromycin cannot be pumped out properly and thus gets its growth inhibited at lower concentration of Azithromycin and this experiment confirms the role of efflux pump inhibitor in antibiotic resistance. A total of 12 isolates $(63.15 \%, n=19)$ showed reduction in MIC of Azithromycin. Figure 3 is represented to show the effect of Esomeprazole in inhibition of efflux pump activity.

\section{Plasmid Profile of Test Isolates}

There was no plasmid in two clinical isolates of the test E.coli. The remaining isolates contained variable number of plasmids (Table 2). There was no visible correlation between occurrence of plasmids and ESBL production.

\section{Detection of the Macrolide Resistance Genes by PCR}

The $m p h(\mathrm{~A})$ gene (403 bp) was commonly present in 14 isolates among 19 isolates(Highest $\mathrm{MIC}>2,048 \mu \mathrm{g} / \mathrm{ml}$ ). The gene was mostly detected in 14 isolates resistant to Ceftriaxone $(73.68 \%$, $\mathrm{n}=19)$ but also in 10 isolates $(52.63 \%, \mathrm{n}=19)$ resistant to only Ceftazidime and 13 isolates (68.42\%, $\mathrm{n}=19$ resistant isolates) resistant to Azithromycin. The gene was detected in 14 isolates, confirming the presence of the gene in multidrug-resistant $E$. coli. In case of the $\mathrm{erm}(\mathrm{C})$ gene (642 bp), which was found in 3 isolates (Highest MIC $512 \mu \mathrm{g} / \mathrm{ml}$ ) were found showing distinct band in previous gel electrophoresis. The $\operatorname{erm}(\mathrm{A})$ gene (533 bp) was present in 2 isolates (Highest $\mathrm{MIC}>2,048 \mu \mathrm{g} / \mathrm{ml}$ ). Table 3 summarizes the MIC values of the test isolates.

Table 1. Primers with their annealing temperatures and sequences used to multiply macrolide resistant genes

\begin{tabular}{lclcc}
\hline Target gene & Primer & Sequence $5^{1} ! 3^{1}$ & $\begin{array}{c}\text { Product } \\
\text { size, bp }\end{array}$ & $\begin{array}{c}\text { Annealing } \\
\text { temperature, }{ }^{\circ} \mathrm{C}\end{array}$ \\
\hline$m p h(\mathrm{~A})$ & mphAFmphAR & GTGAGGAGGAGCTTCGCGAGTGCCGCAGGACTCGGAGGTC & 403 & 60 \\
$m p h(\mathrm{~B})$ & mphBFmphBR & GATATTAAACAAGTAATCAGAATAGGCTCTTACTGCATCCATACG & 492 & 58 \\
erm $(\mathrm{A})$ & ermAFermAR & TCTAAAAAGCATGTAAAAGAAACGATACTTTTGTAGTCCTTC & 533 & 52 \\
erm $(\mathrm{B})$ & ermBFermBR & GAAAAAGTACTCAACCAAATAAATTTAAGTACCGTTACT & 639 \\
erm(C) & ermCFermCR & TCAAAACATAATATAGATAAAGCTAATATTGTTTAAATCGTCAAT & 642 \\
ere(A) & ereAFereAR & GCCGGTGCTCATGAACTTGAGCGACTCTATTCGATCAGAGGC & 420 \\
ere(B) & ereBFereBR & TTGGAGATACCCAGATTGTAGGAGCCATAGCTTCAACGC & 45 \\
& & & 637 & 55 \\
\hline
\end{tabular}


Table 2. Molecular characteristics of the clinical isolates

\begin{tabular}{|c|c|c|c|c|c|}
\hline \multirow[t]{2}{*}{ Isolate } & \multicolumn{5}{|c|}{ Genotypic characteristics of isolates } \\
\hline & $m p h A$ & erm $C$ & ermA & No. of plasmids present & ESBL producer \\
\hline $\mathrm{C} 1$ & - & - & - & 6 & + \\
\hline $\mathrm{C} 2$ & - & - & - & 1 & _ \\
\hline $\mathrm{C} 3$ & - & - & - & 1 & - \\
\hline $\mathrm{C} 4$ & - & - & - & 2 & + \\
\hline C5 & + & - & - & 2 & _- \\
\hline $\mathrm{C} 6$ & + & - & + & 2 & - \\
\hline $\mathrm{C} 7$ & + & + & - & 3 & + \\
\hline $\mathrm{C} 8$ & - & - & + & 0 & _- \\
\hline C9 & + & + & - & 7 & _ \\
\hline $\mathrm{C} 10$ & + & - & - & 1 & + \\
\hline $\mathrm{C} 11$ & + & - & - & 2 & + \\
\hline $\mathrm{C} 12$ & + & - & - & 1 & _. \\
\hline $\mathrm{C} 13$ & + & - & - & 0 & _ \\
\hline $\mathrm{C} 14$ & + & - & - & 1 & - \\
\hline $\mathrm{C} 15$ & + & - & - & 6 & - \\
\hline $\mathrm{C} 16$ & + & - & - & 4 & - \\
\hline $\mathrm{C} 17$ & + & - & - & 3 & $\overline{+}$ \\
\hline $\mathrm{C} 18$ & + & - & - & 2 & + \\
\hline C19 & + & - & - & 1 & \\
\hline
\end{tabular}

Table 3. MIC of different antibiotics for the test isolates

\begin{tabular}{lcccc}
\hline Number of isolates & \multicolumn{4}{c}{ Antibiotic tested } \\
\cline { 2 - 5 } & Azithromycin $(\mu \mathrm{g} / \mathrm{ml})$ & Ceftazidime $(\mu \mathrm{g} / \mathrm{ml})$ & Ceftriaxone $(\mu \mathrm{g} / \mathrm{ml})$ & Imipenem $(\mu \mathrm{g} / \mathrm{ml})$ \\
\hline C1 & 4 & 128 & 512 & 2 \\
C2 & 256 & 0.25 & 256 & 2 \\
C3 & 128 & 64 & 512 & 0.50 \\
C4 & 128 & 0.25 & $>2048$ & 0.50 \\
C5 & 256 & 01 & 64 & 0.50 \\
C6 & 32 & 01 & 512 & 0.50 \\
C7 & 128 & 256 & $>2048$ & 2 \\
C8 & 01 & 04 & 2048 & 0.50 \\
C9 & 01 & 16 & 128 & 2 \\
C10 & 256 & 16 & 256 & 0.50 \\
C11 & 256 & 128 & 256 & 0.50 \\
C12 & 128 & 512 & 16 \\
C13 & 1024 & 2048 & 64 \\
C14 & 1024 & 2048 & 256 \\
C15 & 12 & 2048 & 256 \\
C16 & 128 & 256 & 0.50 \\
C17 & 128 & 512 & 0.50 \\
C18 & 256 & 128 & 2 \\
C19 & 256 & 32 & 16
\end{tabular}

\section{Discussion}

In the present study, all isolates were found to be resistant to Ceftriaxone. A total of $68.42 \%$ of the isolates were resistant to both Ceftriaxone and Ceftazidime. Test for ESBL production became mandatory as higher rate of resistance to ${ }^{2}$-lactam antibiotics has been a common phenomenon. The emergence of extended-spectrum $\beta$-lactamases (ESBLs) in Gram-negative bacteria has increased in recent years, which has led to global 
concern regarding the management of bacterial infections ${ }^{22,23}$. The ESBL enzymes are capable of hydrolyzing broad spectrum Cephalosporins and Monobactams but inactive against Cephamycins and Imipenem. In addition, ESBL producing organisms exhibit co-resistance to many other classes of antibiotics resulting in limitation of therapeutic option. In this study, we found 7 ESBL producers $(36.84 \%, n=19), 11^{2}$ lactamase producers $(57.89 \%, \mathrm{n}=19), 4$ isolates which exhibited ESBL activity against ceftazidime and ceftriaxone $(21.05 \%$, $\mathrm{n}=19), 2$ isolates which exhibited ESBL activity against only ceftriaxone $(10.52 \%, \mathrm{n}=19)$ and 1 isolate which exhibited ESBL activity against only ceftazidime $(5.26 \%, \mathrm{n}=19)$ among nineteen clinical isolates. Though the prevalence of ESBL producers varies with geographical areas and time, a relatively high prevalence rate of ESBL producers in the Asia-Pacific area were documented by several surveillance studies. Previous studies in Bangladesh reported the prevalence of ESBL producers ranging from $23.2 \%$ to $80 \%{ }^{24}$. The discrepancy of the findings between the latter and the present study may be due to the varying prevalence of ESBL producers with time as well as from country to country, city to city and even hospital to hospital in one city. In spite of this, the finding of $36.84 \%$ ESBL producers in the present study is in concordance with earlier reports. The finding of $36.84 \% \mathrm{ESBL}$ producers and $84.21 \%$ Azithromycin resistant isolates is of concern since this indicatesthat these isolates cannot be treated by the specified antibiotics. This also points to the need of determining antibiotic susceptibility in conjunction with MIC values prior to choosing drugs for treatment.

About $84.21 \%$ of the total 19 isolates were found to be resistant to Azithromycin in the study. All of these isolates (100\%) were also resistant to Ceftriaxone, whereas $68.42 \%$ of the isolates were resistant to Ceftazidime and $26.31 \%$ of the isolates were resistant to Imipenem. Of the 19 isolates studied, 26.31\% were resistant to all antibiotics (Azithromycin, Ceftazidime, Ceftriaxone and Imipenem) tested. In a study on antibiotic resistance of different members of the Enterobacteriaceae conducted in Iran, the prevalence of Azithromycin resistant E. coli was found to be $44 \%$ and that of Ceftriaxone resistant isolates of the same species was $56 \%$. Compared to their findings, the much higher prevalence Azithromycin and Ceftriaxone resistant isolates in Bangladesh is a matter of concern ${ }^{25}$. One mechanism of macrolide resistance can be obtained by acquisition of efflux pumps, mef(A) and $m s r(\mathrm{~A})$, that have been found essentially in Gram-positive organisms, although mef(A) has been identified in Gram-negative organisms $^{26}$. In the present study, $\operatorname{mef}(\mathrm{A})$ and $\operatorname{msr}(\mathrm{A})$ were not detected by PCR. However, there was a 2-4 fold reduction in MIC when Azithromycin resistant isolates were exposed to the efflux pump inhibitor, esomeprazole. This indicated that efflux pump played a role in $63.15 \%$ of the tested isolates. Of the isolates that employed efflux pump as a mediator of macrolide resistance, 9 (75\% of efflux pump mediators) also contained $m p h(\mathrm{~A})$ (phosphotransferase) and $1(8.33 \%$ ) contained $\operatorname{erm}(\mathrm{A})$ (esterase); however, none of them contained the gene for $\operatorname{erm}(\mathrm{C})$.
Macrolides may be inactivated by modifying enzymes first reported in Enterobacteriaceae ${ }^{27,28}$ such as esterases encoded by ere(A) or ere(B) genes or phosphotransferases encoded by $m p h(\mathrm{~A}), m p h(\mathrm{~B})$, and $m p h(\mathrm{D})$ genes. The third mechanism is acquisition of efflux pumps, $m e f(\mathrm{~A})$ and $m \operatorname{sr}(\mathrm{A})$, that have been found essentially in Gram-positive organisms, although mef(A) has been identified in Gram-negative organisms ${ }^{26}$. All of these genes confer full cross-resistance between erythromycin and azithromycin ${ }^{29}$.Acquired resistance to macrolides may result from a variety of mechanisms of resistance, several of which have already been reported in Enterobacteriaceae ${ }^{26,29}$. These mechanisms include target site modification by methylases encoded by erm genes, in particular erm(A), erm(B), and erm(C). In the present study, the $\operatorname{erm}(\mathrm{A})$ and $\operatorname{erm}(\mathrm{C})$ genes were detected in $10.53 \%$ of the test isolates each. The isolates that contained erm(A) gene were different from those that contained erm(C) gene. In a previous study in France the 6 genes, $\operatorname{erm}(\mathrm{A}), \operatorname{erm}(\mathrm{C})$, ere(A), ere(B), mef(A), and $\operatorname{msr}(\mathrm{A})$, were not detected in 190 isolates ${ }^{30}$. In contrast to their study where the $\operatorname{erm}(\mathrm{B})$ gene was detected in 2 isolates and the $m p h(\mathrm{~B})$ in 2 other, the present study could not detect any erm $(\mathrm{B})$ or $m p h(\mathrm{~B})$ gene containing isolates.

In this study, the gene for phosphotransferase, $m p h(\mathrm{~A})$ was found to be the most common among the macrolide modifying genes. It was detected in $73.68 \%$ (14 out of 19) of the isolates. Both the isolates that contained $\operatorname{erm}(\mathrm{C})$ also contained $m p h(\mathrm{~A})$, whereas only one isolate (C6) contained both erm(A) and $m p h(\mathrm{~A})$. In a previous study on the distribution of 7 macrolide resistance genes in gram-negative isolates from the urine and oral cavity of healthy children in Portugal, $m p h(\mathrm{~A})$ gene was detected in $57.69 \%$ (15 of 26) $E$. coli isolates ${ }^{26}$. In France, it was found that the prevalence of this gene to be about $17.89 \%{ }^{30}$. Clearly, the much higher prevalence of the antibiotic resistant gene in Bangladesh indicates to the rapid rise and spread of antibiotic resistance owing to the lack of care about completion of the course when taking antibiotic treatments. It might also point to the indiscriminate use of antibiotics and the ready availability of drugs over-the-counter.

\section{Conclusion}

In Bangladesh, currently circulating pathogenic $E$. coli are multidrug resistant. Resistance to macrolides, particularly Azithromycin, is mediated by various factors. Therefore, care must be exercised while prescribing antibiotics.

\section{Competing Interests}

No conflict of interest is declared.

\section{Ethical Approval}

Not required.

\section{Acknowledgment}

We are grateful to the University Grants Commission, Bangladesh for financial support. 


\section{References}

1. Levy SB. 2002. The antibiotic paradox: Da Capo Press.

2. Neu HC. 1992. The crisis in antibiotic resistance. Science. 257(5073): 1064-73.

3. Levy SB. 1997. Antibiotic resistance: an ecological imbalance. Ciba. Found. Symp. 207: 1-14.

4. Normark BH and Normark S. 2002. Evolution and spread of antibiotic resistance. J. Int. Med. 252(2): 91-106.

5. Giedraitien A, Vitkauskien A, Naginien R and Pavilonis A. 2011. Antibiotic resistance mechanisms of clinically important bacteria. Medicina (kaunas). 47(3): 137-46.

6. Walsh C. Antibiotics: Actions, Origins, Resistance (American Society for Microbiology Press, Washington, DC). 2003.

7. Stokes HT and Hall RM. 1989. A novel family of potentially mobile DNA elements encoding site specific gene integration functions: integrons. Mol. Microbiol. 3(12): 1669-83.

8. Paterson D, Ko W, Mohapatra S and Van Gottberg A, editors. Klebsiella pneumoniae bacteremia: impact of extended spectrum beta-lactamase (ESBL) production in a global study of 216 patients. 37th Interscience Conference on Antimicrobial Agents and Chemotherapy; 1997.

9. Steward CD, Rasheed JK, Hubert SK, Biddle JW, Raney PM and Anderson GJ, et al. 2001. Characterization of clinical isolates ofKlebsiella pneumoniae from 19 laboratories using the National Committee for Clinical Laboratory Standards extended-spectrum ${ }^{2}$-lactamase detection methods. J. Clin. Microbiol. 39(8): 2864-72.

10. Shobha K, Gowrish Rao S, Rao S and Sreeja C. 2007. Prevalence of extended spectrum beta-lactamases in urinary isolates of Escherichia coli, Klebsiella and Citrobacter species and their antimicrobial susceptibility pattern in a tertiary care hospital. Indian J. Practising Doctors. 3(6): 01-2007.

11. Jacoby GA and Munoz-Price LS. 2005. The new ${ }^{2}$-lactamases. New Eng. J. Med. 352(4): 380-91.

12. Peirano G and Pitout JD. 2010. Molecular epidemiology of Escherichia coli producing CTX-M ${ }^{2}$-lactamases: the worldwide emergence of clone ST131 O25: H4. Int. J. Antimicrob. Agents. 35(4): 316-21.

13. Livermore DM.1995. Beta-Lactamases in laboratory and clinical resistance. Clin. Microbiol. Rev. 8(4): 557-84.

14. Wong Beringer A. 2001. Therapeutic Challenges Associated with Extended Spectrum, ${ }^{2}$ Lactamase Producing Escherichia coli and Klebsiella pneumoniae. Pharmacotherapy: The J. Human Pharmacology and Drug Therapy. 21(5): 583-92.

15. Levy SB. 1992. Active efflux mechanisms for antimicrobial resistance. Antimicrob. Agents and Chemother. 36(4): 695-703.

16. Poole K. 2005. Efflux-mediated antimicrobial resistance. J. Antimicrob. Chemother. 56(1): 20-51.

17. Pehrsson EC, Forsberg KJ, Gibson MK, Ahmadi S and Dantas G. 2013. Novel resistance functions uncovered using functional metagenomic investigations of resistance reservoirs.Front. Microbiol. 4: 145.
18. Levine MM. 1987. Escherichia coli that cause diarrhea: enterotoxigenic, enteropathogenic, enteroinvasive, enterohemorrhagic, and enteroadherent. J. Infect. Dis. 155(3): 377-89.

19. Murray BE. 1991. New aspects of antimicrobial resistance and the resulting therapeutic dilemmas. J. Infect. Dis. 163(6): 1185-94.

20. Bauer A, Kirby W and Sherris JC. 1966. Turck M. Antibiotic susceptibility testing by a standardized single disk method. Am. J. Clin. Pathol. 45(4): 493

21. CLSI. Performance standards for antimicrobial disk susceptibility tests; approved standard, M31-A3. 3rd ed. Clinical Laboratory Standard Institute, Wayne, PA, USA. 2015.

22. Paterson DL, Mulazimoglu L, Casellas JM, Ko W-C, Goossens H and Von Gottberg A, et al. 2000. Epidemiology of ciprofloxacin resistance and its relationship to extended-spectrum $\beta$-lactamase production in Klebsiella pneumoniae isolates causing bacteremia. Clin. Infect. Dis. 30(3): 473-8.

23. Bourjilat F, Bouchrif B, Dersi N, Claude JDPG, Amarouch H and Timinouni M. 2011. Emergence of extended-spectrum beta-lactamasesproducing Escherichia coli in community-acquired urinary infections in Casablanca, Morocco. J. Infec. Developing Countries. 5(12): 850-5.

24. Islam MA, Huq M, Nabi A, Talukdar PK, Ahmed D and Talukder KA, et al. 2013. Occurrence and characterization of multidrug-resistant New Delhi metallo-2-lactamase-1-producing bacteria isolated between 2003 and 2010 in Bangladesh. J. Med. Microbiol. 62(1): 62-8.

25. Sadeghabadi AF, Ajami A, Fadaei R, Zandieh M, Heidari E and Sadeghi M, et al. 2014. Widespread antibiotic resistance of diarrheagenic Escherichia coli and Shigella species. J. Res. Med. Sci. 19(Suppl 1), S51.

26. Ojo K, Ulep C, Van Kirk N, Luis H, Bernardo M and Leitao J, et al. 2004. The mef (A) gene predominates among seven macrolide resistance genes identified in gram-negative strains representing 13 genera, isolated from healthy Portuguese children. Antimicrob. Agents Chemother. 48(9): 3451-6.

27. Arthur M, Brisson-Noel A and Courvalin P. 1987.Origin and evolution of genes specifying resistance to macrolide, lincosamide and streptogramin antibiotics: data and hypotheses. J. Antimicrob. Chemother. 20(6): 783-802.

28. O'Hara K, Kanda T, Ohmiya K, Ebisu T and Kono M. 1989.Purification and characterization of macrolide 2'-phosphotransferase from a strain of Escherichia coli that is highly resistant to erythromycin. Antimicrob. Agents Chemother. 33(8): 1354-7.

29. Leclercq R. 2002.Mechanisms of resistance to macrolides and lincosamides: nature of the resistance elements and their clinical implications. Clin. Infect. Dis. 34(4): 482-92.

30. Nguyen MP, Woerther P-L, Bouvet M, Andremont A, Leclercq R and Canu A. 2009.Escherichia coli as reservoir for macrolide resistance genes. Emerg Infect Dis. 15: 1648-50. 